\title{
The spread of no-till in conservation agriculture systems in Italy: indications for rural development policy-making
}

\author{
Danilo Marandola ${ }^{1}$, Angelo Belliggiano ${ }^{2^{*}}$, Luca Romagnoli ${ }^{3}$ and Corrado levoli ${ }^{2}$
}

\footnotetext{
*Correspondence: belliggi@unimol.

${ }^{2}$ Department of Agricultural, Environmental and Food Sciences, University of Molise, Via De Sanctis, 86100 Campobasso, Italy Full list of author information is available at the end of the article
}

\begin{abstract}
No-tillage is a farming system aiming at minimizing soil disturbance associated with the cultivation of arable crops. This technique, together with the practices of continuous soil cover and of crop rotation, also represents one of the elements of the so called Conservation agriculture, a paradigm of sustainable agriculture that is spreading in many areas of the globe. The aim of the work is to examine the spread of No-tillage in Italy analyzing the modalities of adoption and the factors that can influence it.

Modalities of adoption can vary depending on whether No-tillage represents an incremental innovation within the ordinary management of the farm, or a complementary element of an alternative technological paradigm identifiable with Conservation agriculture. Factors influencing the adoption of No-tillage, widely studied in the literature, concern the characteristics of the natural environment, the structural features of the holdings (i.e. size) and also the presence of knowledge spillovers that are largely the result of spatial networks between farmers and other stakeholders.

Elaborations have been first of all aimed at distinguishing the two types of modalities of adoption and subsequently at verifying the influence of the factors mentioned above, in particular through the Local Moran Index.

In summary, the work describes how the diffusion of No-tillage practices can be partly ascribed to a cost saving-oriented incremental innovation process in the framework of a conventional paradigm of agriculture that mainly pertain to large size holdings. However, there is a significant number of farms where the adoption of Notillage practices demonstrates the decision to try a more comprehensive reorganization of the way of doing agriculture, similar to the paradigm of Conservation agriculture, and in which the cognitive and relational aspects related to the aforementioned networks seem to be very important.

Spatial analysis has allowed to depict two models of adaptation to the paradigm of Conservation agriculture: one is mainly concentrated in the rural areas of the centralnorthern Apennines, and another is located mainly in two regions of southern Italy (Puglia and Sicily).
\end{abstract}

Keywords: No-tillage, Conservation agriculture, Networks, Rural development policy 


\section{Introduction}

\section{Thematic framework and objective}

No-tillage (NT) is a farming system aiming at minimizing soil disturbance associated with the cultivation of arable crops that is spreading in many areas of the globe, Italy included.

Compared to the traditional tillage-based way of farming, NT can be considered in general terms as an innovation that, as all innovations, has got both technical as well as organizational components. ${ }^{1}$ NT adoption requires specific skills and the use of adequate machineries.

In everyday language NT is often linked to a new vision of agriculture centred on sustainability. This is due to the fact that NT is one of the three main components of Conservation agriculture (CA), ${ }^{2}$ a vision of sustainable farming firmly promoted by FAO also in consideration of its ability to conserve the soil resource. In other words, in the frame of CA, NT can be considered one of the complementary practices aiming at conserving soil and preventing its degradation.

Soil is one of the basic resources for all agriculture production and its protection and restoration represents one of the environmental (and climate) objectives of the Common Agricultural Policy (CAP). The CAP objective of sustainable management of natural resources, and more specifically the provision of environmental public goods and the pursuit of climate change mitigation and adaptation, are actually clearly relevant to the soil protection and improvement. The CAP is an important economic driver for farming decisions across the EU and has the potential to advance soil protection in both agriculture through Member States' and land managers' implementation of its measures and associated obligations.

As is well known, CAP measures available in 2014-20 are the result of a series of incremental reforms since the policy was first introduced in 1962, and some measures relevant to soils have been available for decades. For example, EU Rural development policy support for afforestation and environmental land management contracts dates from the 1980s and CAP cross-compliance originated in requirements for good farming practice first introduced in the 1990s.

Conservation of agricultural soils is a major challenge in Italy. Degradation, erosion, loss of fertility, compaction are relevant issues affecting the agricultural as well as the environmental value of this natural resource. For this reason, soil conservation is one of the main priorities of 2014-2020 Rural development in Italy where 15 out of 21 Rural development programmes (RDPs) ${ }^{3}$ are currently granting support to farmers to adopt soil-friendly practices such as NT under the scheme of Measure $10,{ }^{4}$ with a provisional budget of 280 million euro targeting 192.000 ha of Utilized Agricultural Area (UAA).

The relevance of soil conservation issues in the Italian context, together with the relevance of the budgetary effort provided by the RDPs for, evidently require a more detailed knowledge about the characteristics of the spread of NT in CA in among farmers in order to provide knowledge for improving RDP's decision-making and implementation processes. NT, actually, can play a major role in the conservation of agricultural soils only if adopted in the wider context of the CA approach and not only as a tillage technique merely alternative 
to the to traditional tillage-based way of farming. RDPs should be able to seize this latter aspect to ensure the effective achievement of durable environmental results of soil conservation.

The aim of the work is to examine the spread of No-tillage in Italy analyzing the modalities of adoption and the factors that can influence it.

Concerning modalities, as it will be better clarified further in this paper, we should contemplate that NT can be considered both:

a) an incremental innovation within the already existing technological paradigm (i.e. the traditional tillage-based way of farming), and

b) one of the elements of an alternative farming paradigm based on sustainability (the CA).

In the first case (a) the most relevant issues concern with the adoption and with the process of diffusion of the practice itself. The second case (b) is more complex instead. Together with the issues already mentioned, in this case adoption of NT must relate to problems of adaptation to the context of the entire paradigm of CA, and the solution of these problems requires a wide cooperation among farmers and other stakeholders operating in a certain area.

In this sense, one of the main issues addressed by the work has been to discriminate between the two cases a) and b). This has been done by conveniently processing the data from the last Agricultural Census (2010).

The other central issue has been to identify the main determinants of the process of spread of NT. In this sense, firstly the main references in the literature have been examined in order to create a suitable conceptual framework. Subsequently, a series of elaborations has been carried out on the Census data with the aim to verify the influence by the identified determinants on the process of spread of NT.

Apart from the soil and climate aspects and from some structural features of the holdings, among the factors considered to explain the spread and the related spatial concentration of the phenomenon of the adoption of NT, a key factor has been represented by the presence of networks of farmers and other stakeholders which play a key role in the phenomena of knowledge spillovers, particularly in those situations where the adoption of NT is an element of a more complex transformation that can be assimilated to the CA paradigm.

\section{No-till as a component of a new farming system: the conservation agriculture}

In agriculture a reduction in soil tillage, in many cases, is a choice that does not require particular skills or technical adjustments: if I do a deeper harrowing instead of plowing, ${ }^{5}$ am not doing anything particularly revolutionary in my farm. Maybe this choice is dictated simply by the need to reduce some costs related with soil tillage operations. After changing my soil tillage technique, evidently, I have to check if my choice leads to a decrease in yields and therefore a decrease in revenues, or not. The case would be a bit more complicated if I decide to adopt NT, since for this purpose mechanical and practical adjustments are needed; anyway, even in case I would choose to adopt NT as farming technique, the problem would be not very dissimilar to a case of incremental innovation. On the other hand, it is very different to rethink the way of doing 
agriculture (or of adopting NT) in terms of sustainability as proposed by CA, because it is necessary to rethink the complex of decisions in terms of "overall" sustainability.

Ultimately it is clear thus that CA and NT cannot be considered the same thing. In most of the references listed in the bibliography there is a clear definition of CA: NT plays a key role in CA systems, but it is also emphasized that NT is just one of the requirements (principles) of CA.

CA complies with the generally accepted ideas of sustainability: both in environmen$\mathrm{tal}^{6}$ and socio-economic terms. This latter in particular seems to relevantly affect the adoption process of NT in CA (FAO 2001).

Quite apart the difficulties related to investments for suitable equipment (Guccione and Schifani 2001), from an economic perspective the issues considered in the literature are those related to the impact on costs and revenues related with the adoption of CA. Obviously any reduction of production costs could represent a significant incentive in direction of adopting CA, as shown in some developing countries (Gupta and Sayre 2007).

Cost reduction is largely due to oil and energy saving (Guidobono Cavalchini et al. 2013). FAO (2001) reports economic benefits related also to labour savings and machinery depreciation, and some other authors report CA benefits on investments efficiency and productivity (Marandola and Marongiu 2012). Labour requirements are generally reduced by about $50 \%$, which allows farmers to save on time, fuel and machinery costs (Saturnino and Landers 2002; Baker et al. 2007; Lindwall and Sonntag 2010; Crabtree, 2010). Fuel savings in the order of around 65\% are in general reported (Sorrenson and Montoya 1984; 1991).

On the other hand, effects of CA adoption on yields seem to be limited (Van den Putte et al. 2010). The yield levels of CA systems seem to be comparable with (and, under certain conditions, even higher) than those under conventional intensive tillage systems, which means that CA should not lead to yield penalties.

CA systems, comprising no or minimum mechanical soil disturbance, organic mulch soil cover, and crop species diversification, in conjunction with other good practices of crop and production management, are practiced globally on about $157 \mathrm{M} \mathrm{ha}$, corresponding to about $11 \%$ of field cropland, in all continents and most land-based agricultural ecologies, including in the various temperate environments. This change constitutes a difference of some $47 \%$ globally since 2008/09 when the spread was recorded as $106 \mathrm{M}$ ha. The current total of 157 $\mathrm{M}$ ha represents an increase in adoption of CA by more countries but the estimate is on the conservative side as the updated database does not capture all the CA cropland (Kassam et al. 2015). In the last years CA has consistently expanded, particularly in North and South America as well as in Australia and New Zealand, so CA cannot be considered a temporary fashion (Derpsch and Friedrich 2009). Europe and Africa are the developing continents in terms of CA adoption and uptake. However, because of the good and long lasting research in these continents, showing positive results for CA systems, plus increasing attention being paid to CA systems by governments, European Commission, NGOs, the private sector, international organizations and donors, CA has experienced significant rates of adoption in recent years. For example, CA area in Europe of 2.04 M ha estimated in 2013 is greater by some $30 \%$ than the $1.56 \mathrm{M}$ ha that was estimated in 2008/09 (Kassam et al. 2015).

However in several areas of the world the choice of adopting NT under the "full principles" of CA is not definitive, so the soils are often in a transitional phase, and the benefits of the new farming paradigm proposed by CA cannot be completely obtained 
(Derpsch 2008). Among the main barriers to the adoption of CA practices, actually, there are knowledge on how to do it (know how) and mindset (tradition, prejudice) ${ }^{7}$ (FAO 2008; Friedrich et al. 2009).

Several authors have explored the role of social mechanisms in the generation of the specific knowledge connected to CA and in its spread. Change in tillage and cropping practices requires cooperation between farm and non-farm knowledge (Coughenour and Chamala 2000), and the spread of CA is often the result of specific social networks (Coughenour 2003). The adoption of soil conservation practices requires a growth of social capital (Cramb 2005). Actors promoting CA, often in projects in developing countries, must take into account the specific perception of farmers (Nyanga et al. 2011) and the gap existing between farm and non-farm culture (Moore et al. 2014). The role of social networks seems significant in the above mentioned "transition" (D'souza and Mishra 2016) to the full membership to CA.

Last but not least, literature emphasizes the importance of (social and environmental) context specificities (Andersson and D'Souza 2014), and the difficulties to find general determinants (education, profitability, etc.) to explain the adoption of CA (Knowler and Bradshaw 2007). However cooperation among farmers and other actors plays a key role to promote the necessary mind-set and to adapt CA principles to specific environments.

\section{The conceptual framework: the spread of NT as innovation according to a socio-economic approach \\ Hypothesis suggested by the socio-economic literature}

To describe the spread of NT, almost four paths of socio-economic literature can be involved.

i. The first is the one on diffusion of innovations, starting with the work of Rogers (1962). As well-known his theory - developed really with respect to agricultural innovations in rural context - connects diffusion to the communication process among individuals involved, who have different propensity to adopt. Rogers considers five adopter categories (innovators, early adopters, early majority, late majority, laggards), identifies several social variables related with innovators (among which farm-size), and recognizes the main characteristics of innovations influencing their adoption (relative advantage, compatibility, complexity, trial ability, observability of results). His theory has been widely used in the agricultural extension services, but has been broadly criticized mainly for considering innovation as always appropriate, regardless end-users (and context's) needs.

ii. The second one is the literature on adoption of crop varieties within the framework of households models (e.g. de Janvry et al. 1991), that considers many factors affecting adoption process (see e.g. Awotide et al., 2016, Simtowe et al. 2016). Letaa et al. (2015) recently summarized these factors: individual and household features (age, gender, education, etc.), farm characteristics (soil fertility, size - that can help to overcome the costs of trial, specialization, etc.), location and contextual factors (social networks, etc.).

iii. The location factor brings us to the third large body of literature concerning spatial location patterns of economic activities. It is well known that differences of spatial location can be ascribed to three broad 
classes of factors (Hoover 1937): differences in natural resources endowment (e.g. soil and climate, etc.), market access, and spatial agglomeration externalities (Ievoli et al. 2017). The latter are usually related to: economies of scale (in our case, again, farm size), location economies ("within" sector, that mainly concern skilled workers, specialized services as contractors, and information spill-over), and "between-sectors" externalities, mostly (again) knowledge spillovers (see Duranton and Puga 2001).

iv. The last path can be defined as the evolution of innovation approach in agriculture and rural development. This process has benefited from the more general theoretical developments concerning the role of technical change in economic theory, which stresses, by the way, the endogenous character of innovation that is generated in departments of R\&D of large companies, but also in much wider processes of learning: by doing, by using and by interacting (Lundvall 1995). In this framework - overcoming the "historical" distinction between discovery push and demand pull - it is customary to distinguish between the "global" directions of technical change and the technical advances as possible within a single direction. In a nutshell, in this framework it is clearly assumed the distinction between "technological paradigms" (Dosi 1982) and the processes of "incremental innovation". The context of selection of paradigms goes beyond markets and includes several connected institutions, that, as a whole, represent the "innovation system" (on all these issues see Dosi et al. 1988). This way of thinking it is spread in the society and in the policies as testified by the diffusion of expressions like: interactive approach, systemic approach, multi-actor approach, user-centric approach, participatory approach, co-create knowledge approach, etc., also in agricultural context. Just think to innovation in European agricultural policy, and the role assigned to "Agricultural Knowledge and Information Systems", concisely AKIS (EU SCAR 2012). However, to recognize the need of a systemic approach does not imply that the existing AKIS and, more in general, the innovation systems of the various agricultures are really operating in a systemic way, that their actions are coherent with the effective farming problems, and with the needs of rural areas as a whole (see e.g. Van der Ploeg 2003). This has called for a process of rethinking of innovation in agriculture and rural areas (Knickel et al. 2009), driven by a sustainability perspective rather than a "modernization paradigm", genuinely systemic, with redefined public and private goals, capable to consider farmers' novelties and to interact (trough hybrid networks) with local tacit knowledge. The latter is an important element to consider in the interpretation of geographical concentration of innovation.

\section{The conceptual framework}

To interpret the spread of NT, we assume that the effective adoption of this innovation implies profitability for the holdings. In other words, the presence of the method in a farm located in a certain area implies that in that farm (and context) the profit associated with adoption of NT is positive.

If we observe the presence of NT in a certain farm, the next step is to interpret the choice of NT considering the several factors above considered. 
Obviously in our case natural resources play a relevant role, in particular soil and climate. NT is often associated with critical issues concerning soil (erosion, desertification), and these problems affect more areas than other (in Italy they depend to a large extend by latitude).

The adoption of NT can take place in a "conventional" paradigm within which it represents an incremental innovation. Considering that the method is mainly cost-saving it is realistic to assume that size can be the main factor involved, (maybe organizational form and age too). It is also realistic postulate that within this framework the choice of the NT will not necessary concern the entire farm's UAA.

The choice of NT can be an element of a novelty developed by farmers within an alternative paradigm (CA). In this case adaptation processes to context are very relevant. In a sustainable perspective crop rotations are complementary to NT. To adopt CA, it is necessary to redefine the entire type of farming most probably considering the entire UAA. The size and the presence of specialized services (contractors) can influence the realization of such "global conversion". It could also be relevant the presence of knowledge spillovers, proven by the existence of networks of farmers and other stakeholders.

The last determinant of adoption to consider concerns the presence of political support connected with Common Agricultural Policy that can influence the adoption of NT.

In the current 2014-2020 phase, as mentioned above, there are some payments under the scheme of Measure 10 that support farmers to adopt soil conservation behaviors. However, our data in refer to a period that precedes the current new programming cycle, so that such influence cannot be assumed.

\section{Data sources and methods}

Data sources and elementary data

On the basis of the conceptual framework it is clear that the elements on which it has been intended to investigate through the empirical survey are:

- the localization of the NT phenomenon,

- the size of the holding and the age of the farmer,

- production specialization,

- the presence of local networks.

The Agricultural Census $(2010)^{8}$ collected useful information concerning the adoption of NT in agricultural holdings and concerning the abovementioned elements. More specifically the work has been based on the elementary data provided by the Census for the 52.218 agricultural holdings (population "P-NT" from now on) declaring a Arable Utilized Agricultural Area (A-UAA) under NT greater than zero hectares; thus, 52.218 agricultural holdings declaring to have at least a part of the arable land under NT farming schemes. ${ }^{9}$

A series of elaborations have been subsequently carried out on this P-NT population to a) distinguish the two adoption models (incremental and paradigmatic) and, at the same time, to b) consider the above mentioned elements (size, type of farming, networks). As will be described further in the paper, some of these elaborations have been based on a heuristic filtering procedure and a part on statistical procedures, both 
descriptive and inferential (Local Moran's). The heuristic filtering procedure has been carried out to discriminate among the cases of adoption of NT as incremental innovation or as membership to the CA, and to discriminate the influence of the legal system of the holdings. Here we describe first P-NT population.

Within the whole collective of P-NT, the ratio between the amount of A-UAA under NT schemes and the total A-UAA surveyed by Census is $46,0 \%$ and shows variability at regional and local scale. Figure 1 reports the distribution of this ratio at Italian level basing on the 8.092 municipalities [Local Administrative Units (LAU) 2] into which Italy was subdivided at Census date.

There are many municipalities with (at least) a part of the surveyed A-UAA under NT farming schemes (5.171 out of 8.092 municipalities, corresponding to $63,9 \%$ ). The majority of them is anyway concentred in the last quintile (80-100\%). This means that where practiced, NT techniques tend to be adopted by P-NT holdings on a significant part of the held A-UAA. The average size of the arable land (A-UAA) in P-NT holdings adopting NT on the $100 \%$ of the surveyed A-UAA is greater than the farm average A-UAA reported by Census in Italy for the 1,62 million surveyed agricultural holdings ("P-TOT" from now on).

The 52.218 agricultural holdings declaring to have at least a part of the total arable land under NT farming schemes (P-NT population) account for the 3\% of P-TOT and for the $6 \%$ of the total UAA surveyed in Italy. These farms adopt NT practices at least on a certain amount of their A-UAA, but no more information is made available by this data on the typology and features of the CA principles they implement beyond the sole NT practice.

P-NT holdings, anyway, have special characteristics as compared with P-TOT. In this population, for instance, the amount of holdings having a legal system of "individual firm" is significantly lower than the one observed in P-TOT (92\% vs. 96\%). This gap is compensated by a higher amount of companies, especially the typology of "individual companies", who represent the $6 \%$ in P-NT versus the $2,5 \%$ in P-TOT. Other more complex typologies of companies ("limited companies", "cooperatives" etc.) are also more abundant in P-NT (1,6\%) compared with P-TOT (1\%). ${ }^{10}$

The most important characteristic of P-NT compared with P-TOT is anyway the size expressed in UAA. The average size of P-NT is actually 15,1 ha, almost twice compared with the size of P-TOT (7,9 Ha).

Farmer's age does not seem to be a significant characteristic of P-NT holdings. Holders younger than 40 (as stated by CAP regulations for the definition of "young farmer") represent $11,1 \%$ of total P-NT holders (a little bit more than the $9,9 \%$ in P-TOT). We must observe, anyway, that farmers under the age of 54 represent the $41 \%$ of P-NT (vs.38\% observed in P-TOT).

\section{Methods: filtering procedures and spatial distribution of NT holdings}

In order to identify and describe the spread of NT in Italy under the full principles of the CA farming paradigm, a sequence of filtering operations has been implemented on the elementary data made available by the Census for $\mathrm{P}-\mathrm{NT}$ recalling the basic principles adopted by FAO for CA data collection and definition. 


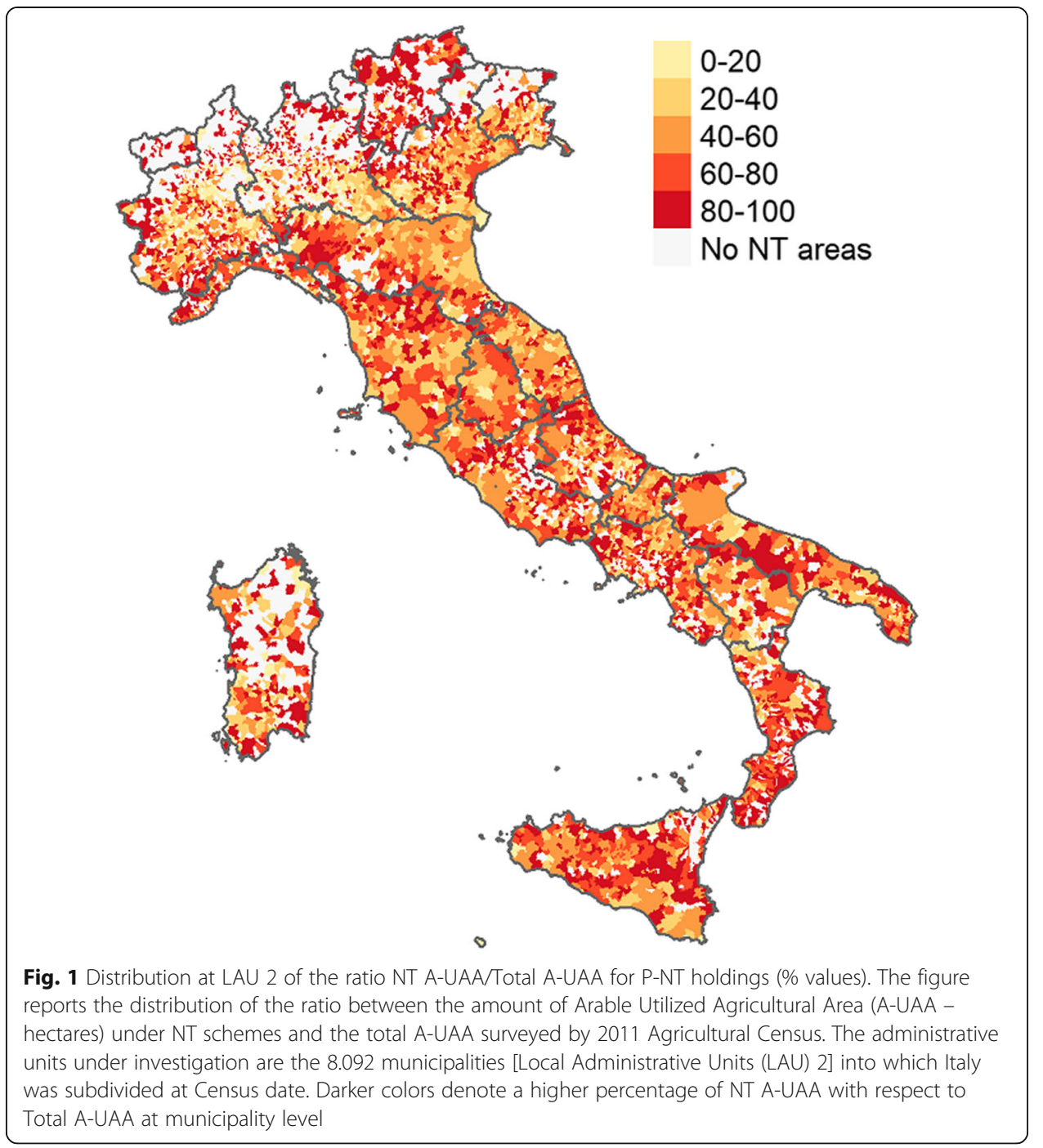

Census does not provide data on organic soil cover and crop rotations/associations linked to the adoption of NT practices, but only info on the adopted soil tillage practices (that is the most important pillar, but not the sole, of $\mathrm{CA}$ ). In this frame, filtering operations were implemented on Census data in order to exclude from the initial P-NT all the farms adopting NT practice as an occasional choice (in a conventionally managed farming system) instead of a permanent practice within a permanent CA regime. A synthesis and description of the filtering operation performed on Census data is reported in Table 1.

The filtering procedure returned two interesting statistical collectives of NT farms supposed to be characterized by different degrees of engagement with CA principles. These are the P-NT100\% (21.033 holdings) and the P-CA (5.328 holdings). P-NT100\% represents the family of agricultural holdings practising NT on the $100 \%$ of the A-UAA (but we have no indications on how and why they do so); P-CA represents a (very) restricted collective of holdings that, in consideration of the combination variables described above, we assume to be more probably practicing NT under "real" CA schemes in Italy. The average size has been calculated for these two groups at regional level. 
Table 1 Description of the filtering operations performed on Census elementary data

\begin{tabular}{ll}
\hline Filters & Filtering operation \\
\hline Filter 1: excluding from P-NT the & We filtered P-NT (52.218 \\
holdings who declare A-UAA under & agricultural holdings) keeping \\
different tillage schemes in addition to & the agricultural holdings only \\
NT and keeping holdings practicing & declaring NT as tillage practice \\
only NT as simplified soil farming & and excluding the ones \\
technique. & declaring also MT and CT on a \\
& certain share of the A-UAA. \\
& After applying this first filter, \\
& the total population of \\
& holding decreased to 27.338 \\
& ("P-NT ONLY").
\end{tabular}

Filter 2: excluding from P-NT the holdings with NT A-UAA $<100 \%$ of the total A-UAA.

Filter 3: excluding from P-NT the holdings with A-UAA devoted to the cultivation of corn and open-field vegetables.

Filter 4: excluding from P-NT the holdings with A-UAA cultivated for forage/hay production.

Many of P-NT ONLY holdings have a total A-UAA greater we filtered P-NT ONLY excluding those holdings for which total A-UAA resulted $>$ of the A-UAA declared under NT. After this second filter, we obtained a total of 21.033 holdings ("P-NT100\%").

We filtered 21.033 P-NT100\% excluding holdings cultivating corn/maize and open-filed vegetables in A-UAA: this third filter reduced our P-NT100\% population to a total of 19.498 holdings ("P-NT100\%NoC-V");

We filtered P-NT100\%NoC-V population excluding holdings cultivating exclusively
Rationale

It is reasonably possible that farmers practicing NT, but also other soil tillage techniques in their holdings, are not operating under CA principles, but simply adopting NT as an occasional practice on a share of the A-UAA. than the area under NT. Thus, hay/forage (even if in rotation with other crops) on the 100\% of the declared A-UAA and keeping all the other holdings with the ratio hay-forage A-UAA/total A-UAA < 1). This last filter was very restrictive since the final number of holdings is composed by 5.328 remaining agricultural holdings ("P-CA"). After all these filtering operations, we assume that this P-CA population of agricultural holdings could represent the population of farms practicing in Italy NT under the real principles of CA.
It is reasonably possible that holdings practicing NT only on a share of the total A-UAA are not fully operating under CA principles, but simply adopting NT as an occasional practice.

Corn is a very profitable crop in productive. The same happens with open-field vegetables in arable land. Where irrigation is available, corn and open-field vegetables tend to be mono-cultivated or, anyway, tend compensate soil compaction determined by heavy machineries traffic. Moreover, vegetables are normally transplanted (not drilled) and this requires dedicated soil tillage operations. In this frame, it is reasonably possible that holdings cultivating corn and open-field vegetables tend to adopt NT as an occasional practice more than as a part of a consolidated CA system.

Production of forage is quite common in Italy, especially in more marginal areas. Cultivation of hay normally do not require any specific or heavy preliminary reason, it is reasonably possible that holdings declaring to hold A-UAA for the production of forage/hay in rotation with other arable crops tend to adopt NT as an occasional practice more than as a part of a consolidated CA system. Italy and requires irrigation to be to require soil tillage operation to soil tillage operations. For this 
The distribution at level of municipality of the holdings belonging to P-NT100\% and P-CA is provided in Fig. 2. P-NT100\% is the population of NT holdings (n. 21.033) deriving from filtering operation n. 2; P-CA is the most restricted collective of NT holdings (n. 5.328) deriving from filtering operation n. 4. As it could be expected, at national scale, the number of municipalities with no holdings practicing NT according the characteristics of the two groups is quite high: 4.109 for P-NT100\% and 5.934 for P-CA, respectively the $50,1 \%$ and $73,3 \%$ of the total number of Italy's municipalities.

The geographic distribution of the holdings practicing NT is different in the two groups: while municipalities with the higher number of P-NT100\% holdings tend to be situated in central and northern regions of Italy $^{11}$ (a), P-CA holdings tend to gather more densely in southern municipalities of Sicily and Apulia, with the sole exception of eastern Emilia Romagna (b).

The spatial distribution of NT agricultural holdings is a central issue for the purpose of this paper, since it allows to identify possible phenomena of networking among NT holdings. These phenomena can be somehow described by how NT holdings tend to cluster within the municipalities.

The existence of significant clusters of similarly-behaving municipalities (i.e. clusters of municipalities with similar number of holdings practising NT techniques) can be obtained by means of some spatial statistics tools as the one that rely on the well-known concept of global and local spatial autocorrelation. The notion of spatial (auto)correlation implies that, given the spatially indexed observations $x_{1}, x_{2}, \ldots, x_{i}, \ldots, x_{n}$, the values observed at the $i$-th data site (the $i$-th administrative unit, in our case) are related to the values observed at neighboring locations: we refer to positive spatial autocorrelation when similar values of $x_{i}$ occur in its neighborhood, $N_{i}$. On the contrary, negative spatial autocorrelation indicates that neighboring values of $x_{i}$ are dissimilar.

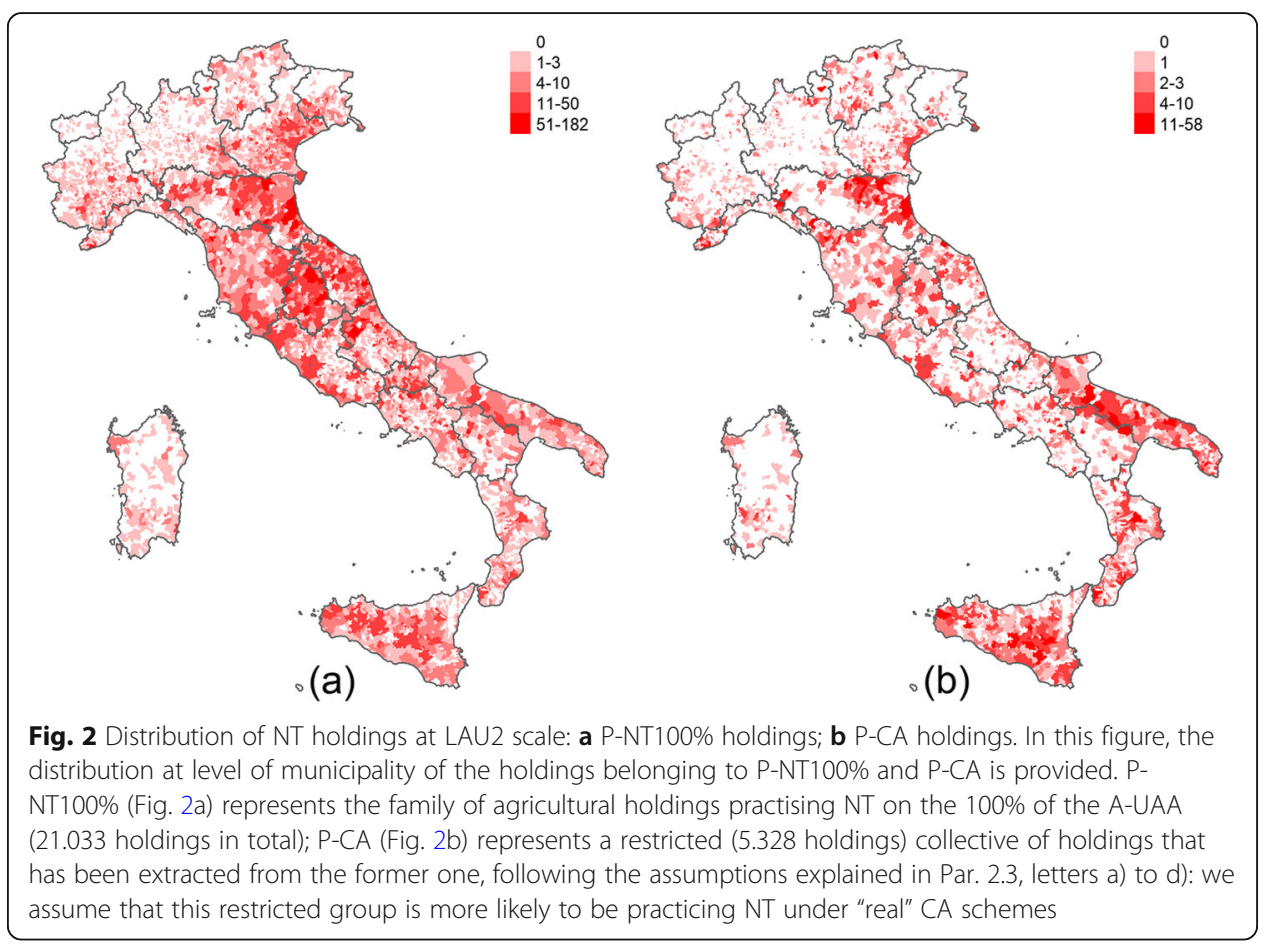


A global measure of autocorrelation gives a unique value summarizing spatial association with respect to the whole region under study.

The most used index of autocorrelation is the well-known (global) Moran's I where $z_{i}$ $=x_{i}-\bar{x}$, and $w_{i j}$ is a measure of the spatial contiguity between spatial units $i$ and $j$ :

$$
I=\frac{n}{\sum_{i=1}^{n} \sum_{j=1}^{n} w_{i j}} \frac{\sum_{i=1}^{n} \sum_{j=1}^{n} w_{i j} z_{i} z_{j}}{\sum_{i=1}^{n} z_{i}^{2}}
$$

The choice of the spatial weights $w_{i j}$ is itself a challenging task, and lots of proposals have been made in literature. Anyway, the simplest and even the most followed solution is that of imposing a first order dichotomous contiguity: $w_{i j}=1$ if zones $i$ and $j$ share a part of common boundary, $w_{i j}=0$ otherwise. This has been our choice, too: the weights have been stored into a $8078 \times 8078$ square matrix $W$, a bit less than the number of municipalities according to the Census (14 municipalities have no common boundaries, i.e. extraterritorial municipalities or small islands).

In brief, Moran's I is a regression coefficient, calculated between the original variable, $z_{i}$, and the spatially lagged variable $\sum_{j=1}^{n} w_{i j} z_{j}$. It is greater than 0 if there is positive spatial correlation between the two variables (it is the case in which $z_{i}$ 's tend to assume similar values in contiguous zones); it is negative in the opposite case - the $z_{i}$ 's and its neighbors tend to assume opposite values with respect to the global mean.

The results of Moran's I derivation, ${ }^{12}$ for the variable under study (i.e. the number of agricultural holdings per municipality) in P-NT100\% and P-CA groups, are reported in Table $2^{13}$ :

The class of Local Indicators of Spatial Associations (LISA) is the natural extension of spatial autocorrelation analysis: they give, for each point in space, an indication of significant spatial clustering of similar or dissimilar values around the point. A major feature of a LISA is its capability of detecting this clustering process and show us the location of both kinds of departure from no autocorrelation.

Local Moran's I (LM) (Anselin 1995) is one of the best-known LISA: it is a decomposition of the global Moran I into its individual components, and calculates a Moran's I with respect to each of the local networks formed by a zone and its neighbors:

$$
I_{i}=\frac{z_{i} \sum_{j=1}^{n} w_{i j} z_{j}}{\sum_{i=1}^{n} z_{i}^{2} / n}
$$

The meaning of the LM index is the same as global I, but at a local level: in this way, knowing that the mean of all the LM is equal to the global I, we are able to interpret the individual $I_{i}$ 's as indicators of significant local spatial clusters. Also in this case,

Table 2 Results of Moran's I derivation

\begin{tabular}{lll}
\hline Group & I value & (pseudo) p-value \\
\hline P-NT100\% & 0.307 & 0.0001 \\
P-CA & 0.220 & 0.0001 \\
\hline
\end{tabular}


inference is carried out through conditional randomization: the value $z_{i}$ is kept constant, while all other neighboring values are randomly permuted.

The typical presentation of the results considers two maps: a) the significance map, a map presenting, for each zone, the inferential procedure result in terms of "pseudo" $p$-values; and b) the LM cluster map, another map presenting the result of the comparison, at local level and only for the zones giving a significant $p$-value (usually, pseudo $p<0.05$ ), between the values $z_{i}$ and $\sum_{j=1}^{n} w_{i j} z_{j}$ With the LM cluster map we can have four different combinations of High $(\mathrm{H})$ and Low (L) values that allow to easily understand the kind of local clustering around zone $i$ (Table 3).

The combinations $\mathrm{H}-\mathrm{H}$ and $\mathrm{L}-\mathrm{L}$ give positive contribution to global I: when statistically significant, this means that we are in the presence of values (respectively) higher $(\mathrm{H}-\mathrm{H})$ or lower $(\mathrm{L}-\mathrm{L})$ than global mean, both for the observed variable and the linear combination of its neighboring zones.

In this paper we have been principally interested in $\mathrm{H}-\mathrm{H}$ cases since they represent hot spots of municipalities with a high number of P-CA holdings that we assume to gather in such places because they are somehow cooperating to develop together CA farming practices.

\section{Results and discussion}

P-NT100\% counts for the 40.2\% of P-NT holdings (n. 52.218). In comparison with P-NT, in P-NT100\% "Individual companies" count for a smaller amount (2.7\% vs. $6 \%)$. The amount of "more complex typologies of companies" (1.41\% vs. $1.6 \%)$ and "individual firms" (94.6\% vs. 92\%) instead do not show relevant differences.

Average UAA is 6.8 ha in P-NT100\% and results actually lower than the average UAA of P-TOT (7.9 ha). The lower average of UAA hold by farmers is confirmed also in the very restricted population of P-CA holdings (7.6 ha). This evidence raised the need to check any significant difference of this phenomenon at regional scale giving priority to regions where more positive spatial autocorrelation between P-NT100\% holdings have been found (Fig. 3a).

As shown in Fig. 3a, Emilia Romagna, Umbria, Tuscany and Marche Region are the areas where P-NT100\% holdings tend to have higher values of LM. They keep on showing anyway an average UAA significantly lower than the one hold by P-TOT.

P-CA holdings with higher values of LM, on the contrary, are mainly concentred in Apulia and Sicily (Fig. 3b). The size of these latter holdings is higher than the average UAA in P-TOT: + 7.5 ha on the average UAA in Apulia and + 5.2 ha for the same entry in Sicily (Table 4). The average UAA is lower in P-CA holdings of Emilia Romagna in comparison with P-TOT (- 6 ha).

The existence of "High-High" clusters in the three regions cited above (Fig. 3c) suggests the presence of farmers' networks interested or motivated in cooperating to adopt NT, in accordance with local tacit knowledge, under the whole principles of CA. These clusters also aggregate the majority of the municipalities interested by spatial

Table 3 Possible combinations determining the sign of LM index, $I_{i}$

\begin{tabular}{lll}
\hline & $\sum_{j=1}^{n} w_{i j} z_{j}>0$ & $\sum_{j=1}^{n} w_{i j} z_{j}<0$ \\
\hline$z_{i}>0$ & High-High $\left(I_{i}>0\right)$ & High-Low $\left(I_{i}<0\right)$ \\
$z_{i}<0$ & Low-High $\left(I_{i}<0\right)$ & Low-Low $\left(I_{i}>0\right)$ \\
\hline
\end{tabular}



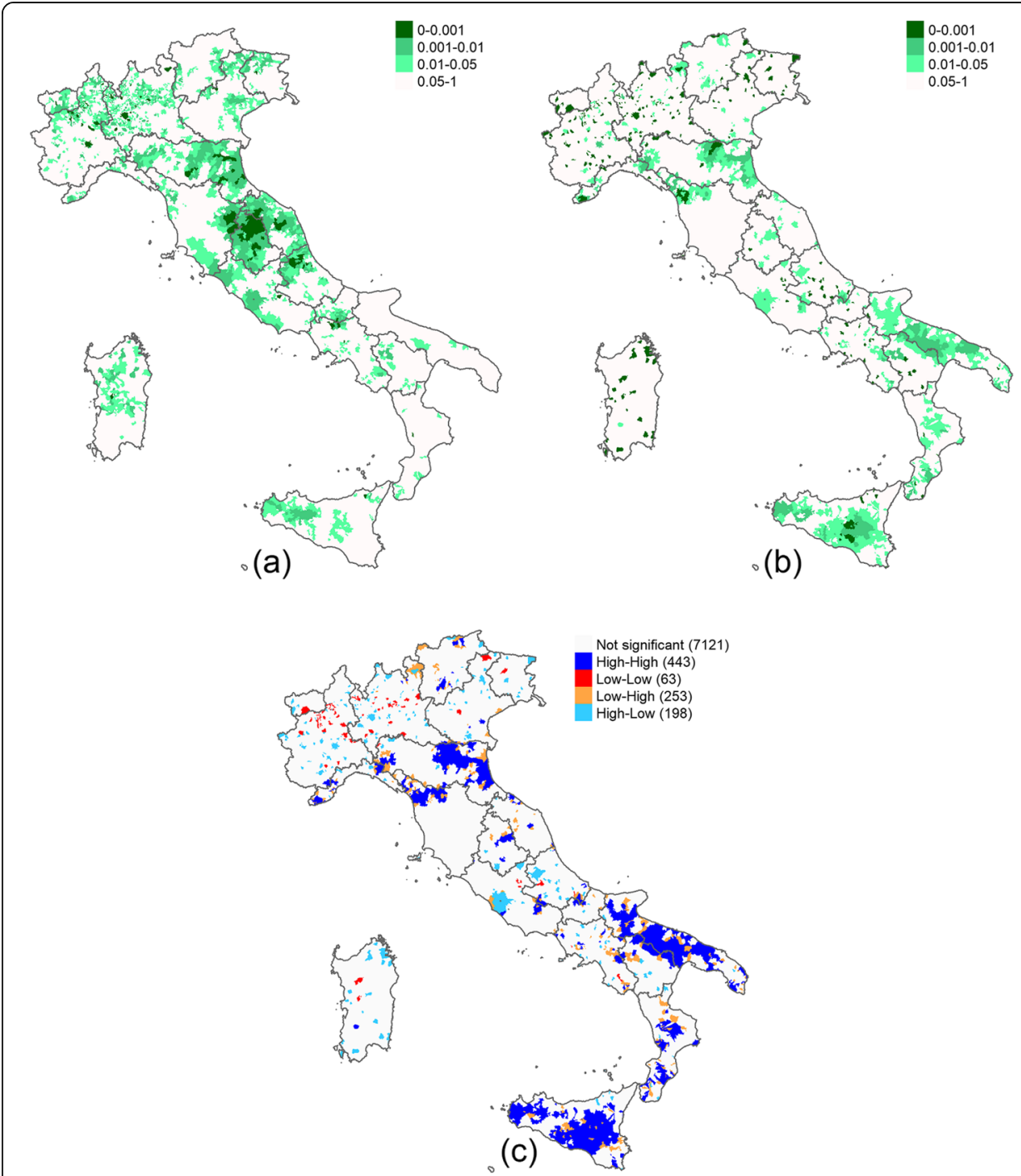

Fig. 3 Number of agricultural holdings per municipality: a LISA significance map for P-NT100\%; b LISA significance map for P-CA group; (c) LISA cluster map for P-CA. Figure 3a and b show the Local Moran's i $_{i}$ (pseudo) p-values at municipality level for, respectively, P-NT100\% and P-CA holdings. Lower values mean more significantly different from zero values for the LM, that is, a significant departure from the null hypothesis of no autocorrelation; usually, a p-value less than 0.05 is considered as identifying a local cluster. Figure $3 \mathrm{C}$ is the LM cluster map for the most interesting group of P-CA holdings: the blue spots $(\mathrm{H}-\mathrm{H}$ combinations) indicate that there are groups of (geographically contiguous) municipalities in which the number of P-CA holding is significantly higher than the mean; the presence of such clusters suggests the presence of informal farmers' networks interested or motivated in cooperating to adopt NT under the whole principles of CA

autocorrelation (46\%), resulting evidently predominant in Apulia (72.8\%), Sicily (72.5\%) and Emilia Romagna (69\%).

Lastly we must observe that for both families of NT holdings (P-NT100\% and P-CA) the amount of young farmers is low.

Ultimately, we can argue that there is a number of cues that characterize each one of the three groups of NT holdings (P-NT, P-NT100\% and P-CA), giving special features to each one of them: geographical distribution, size in UAA, typology of the legal system, productive specialization, spatial autocorrelation. 
Table 4 Average UAA per holding

\begin{tabular}{|c|c|c|c|c|c|c|c|}
\hline \multirow[t]{2}{*}{ Regions } & \multirow{2}{*}{$\begin{array}{l}\text { P-TOT } \\
\text { UAA (ha) }\end{array}$} & \multicolumn{2}{|l|}{ P-NT } & \multicolumn{2}{|l|}{ P-NT100\% } & \multicolumn{2}{|l|}{ P-CA } \\
\hline & & UAA (ha) & $\begin{array}{l}\text { Diff. } \\
\text { P-TOT (ha) }\end{array}$ & UAA (ha) & $\begin{array}{l}\text { Diff. } \\
\text { P-TOT (ha) }\end{array}$ & $\overline{\text { UAA (ha) }}$ & $\begin{array}{l}\text { Diff. } \\
\text { P-TOT (ha) }\end{array}$ \\
\hline Piedmont & 15.1 & 17.5 & 2.4 & 7.6 & -7.5 & 6.0 & -9.1 \\
\hline Valle d'Aosta & 15.6 & 24.7 & 9.1 & 28.4 & 12.8 & 24.2 & 8.6 \\
\hline Lombardy & 18.2 & 22.4 & 4.2 & 5.6 & -12.6 & 4.0 & -14.2 \\
\hline Trentino A.A. & 10.3 & 8.8 & -1.5 & 6.2 & -4.1 & 5.4 & -4.9 \\
\hline Veneto & 6.8 & 9.0 & 2.2 & 3.7 & -3.1 & 5.1 & -1.7 \\
\hline Friuli VG. & 9.8 & 13.3 & 3.5 & 3.9 & -5.9 & 6.3 & -3.5 \\
\hline Liguria & 2.2 & 2.6 & 0.4 & 3.3 & 1.1 & 3.0 & 0.8 \\
\hline Emilia R. & 14.5 & 26.1 & 11.6 & 7.7 & -6.8 & 8.5 & -6.0 \\
\hline Tuscany & 10.4 & 20.3 & 9.9 & 8.2 & -2.2 & 7.6 & -2.8 \\
\hline Umbria & 9.0 & 13.6 & 4.6 & 6.6 & -2.4 & 8.3 & -0.7 \\
\hline Marche & 10.5 & 17.1 & 6.6 & 6.7 & -3.8 & 8.0 & -2.5 \\
\hline Lazio & 6.5 & 13.1 & 6.6 & 6.8 & 0.3 & 5.4 & -1.1 \\
\hline Abruzzo & 6.8 & 10.2 & 3.4 & 5.7 & -1.1 & 3.2 & -3.6 \\
\hline Molise & 7.5 & 10.4 & 2.9 & 6.5 & -1.0 & 7.9 & 0.4 \\
\hline Campania & 4.0 & 6.8 & 2.8 & 4.7 & 0.7 & 3.8 & -0.2 \\
\hline Apulia & 4.7 & 16.4 & 11.7 & 12.7 & 8.0 & 12.2 & 7.5 \\
\hline Basilicata & 10.0 & 15.3 & 5.3 & 11.1 & 1.1 & 15.1 & 5.1 \\
\hline Calabria & 4.0 & 7.6 & 3.6 & 5.4 & 1.4 & 5.8 & 1.8 \\
\hline Sicily & 6.3 & 13.6 & 7.3 & 9.1 & 2.8 & 11.5 & 5.2 \\
\hline Sardinia & 19.0 & 34.2 & 15.2 & 25.0 & 6.0 & 25.2 & 6.2 \\
\hline ITALY & 7.9 & 15.1 & 7.2 & 6.8 & -1.1 & 7.6 & -0.3 \\
\hline
\end{tabular}

In P-NT seems to be particularly relevant the overall average size of the holdings (UAA) compared with P-TOT (Table 4). The average size of P-NT is actually 15.1 ha, more than twice compared with the size of P-TOT (7.9 ha). This represents an additional indication of how important (or binding) is, in general, the dimensional scale factor in the adoption of NT practices. Also in consideration of the geographical distribution of P-NT holdings on the national territory, we can state that the main characteristics of this group result influenced by the features of big-sized farms (not necessarily extensive farms) who sporadically, and in a limited manner, adopt NT practices. P-NT is a very heterogeneous collective of holdings.

The more pronounced organization of P-NT holdings under "company" schemes, anyway, could represent a first indication of how P-NT farms need to look for more efficient organizational layouts to tackle the modernization needs, especially on the mechanization side (and thus, require to shift from CT to NT).

In P-NT100\%, but also in P-CA, overall average size (UAA) is not different from the average farm UAA in P-TOT. Geographical distribution changes instead and, in consideration of the results of filtering operation n.4, we assume that the characteristics of the P-NT100\% group are relevantly influenced by hay/forage production-oriented farms. P-NT100\% is evidently characterized by extensive farming systems mainly devoted to animal husbandry. It represents somehow an "Italian way" of adopting CA principles, adapting them to the cultural and farming tradition (local tacit knowledge) 
of Italy's Apennine areas. A conservation farming system where the other two CA principles beyond NT (soil cover and crop rotation) seem to be not so relevant as soil minimum disturbance evidently is. Linkages with the territory seem to be important for this kind of CA system and the existence of strong spatial autocorrelation suggests the ongoing creation of networks among NT farmers and other stakeholders (advisors, contractors and research centres).

P-CA group was hidden by P-NT100\% and came out after the last filtering step. Farm size (UAA) becomes again an important factor for these holdings, at least in two of the regions where P-CA holdings with higher values of LM have been found, confirming hypothesis concerning the importance of the dimensional scale factor in the adoption of NT practices. This is confirmed in Apulia and in Sicily, two southern regions of Italy with relevant soil degradation problems, where the average UAA of P-CA holdings results higher than average UAA of P-TOT (respectively +7.5 ha in Apulia and +5.2 ha in Sicily). This is not confirmed in P-CA holding of Emilia Romagna where high values of spatial autocorrelation have been also found. This evidence seems to provide the economic justification to the shift from conventional soil tillage-based farming to NT practices and stable CA schemes of farming. It is supposed actually that bigger farms are the ones who can better face investments and risks related to the conversion and even get from it more advantages in terms of economic benefits than smaller farms can do. The reduction of the average UAA that remains evident in P-CA holdings of Emilia Romagna in comparison with P-TOT ( -6 ha) suggests anyway the existence of other possible criteria for the aggregation of P-CA holdings in this region and rises the need to go more in depth with qualitative comparative surveys with Sicily and Apulia to gather further elements of knowledge on clustering processes. For P-CA holdings clustering in Sicily and Apulia, the features of the landscape and of the farm productive processes traditionally require soil tillage operations. In this sense the adoption of NT practices in P-CA holdings in Apulia and Sicily could be interpreted as a deliberated choice/attempt of operating under the CA principles. Especially for holdings clustering in Sicily and Apulia, this process is argued to be facilitated by social networks of farmers as suggested by Local Moran's Index values, but on this latter aspect more qualitative investigation would be needed.

\section{Conclusions}

The diffusion of NT can be in part predominantly assimilated (this is worth for about the $50 \%$ of agricultural holdings practicing NT) to a process of incremental innovation as part of a cost-reduction strategy, in the framework of a conventional tillage farming paradigm. This is a model in which the dimensional factor assumes significant importance and where NT represents a process that can be activated in parallel with the other production processes, on a more or less consistent area of the holding. In this case the adoption of NT is not necessarily ascribable to discourses of sustainability and is not necessarily evidence of a shift toward CA farming systems.

In part, however, the adoption of NT seems to suggest the will and/or the necessity of a part of the holdings that practice it to proceed to a more comprehensive reorganization of the way of doing agriculture, to adhere to a new paradigm, that it can be likened to the CA, with all the implications, even economic, that this entails. 
More precisely, filtering the whole group of P-NT holdings, we found two prototypes of NT holdings (P-NT100\% and P-CA) that could be considered more close to the paradigm of $\mathrm{CA}$ and represent a real shift toward it. For both models, context characteristics (at landscape and farm level) seem to be relevant. Soil degradation processes and vulnerability to drought in Apulia and Sicily could confirm this hypothesis.

P-NT100\% is a collective of holdings strongly influenced by the typical characteristics of the farms located in central Italy. It actually recalls a farm model typical of mid-Apennine rural areas. At the roots of this model we can find economic (mainly cost savings) as well as environmental motivations (especially reduction of soil and water losses) with relevant economic implication in the long-term. The geographical characteristics of the farm model proposed by P-NT100\% suggest that eventual know-how and economic/technical barriers due to limited farm sizes (first of all the purchase of dedicated technologies) have been overtaken, probably with the support of external factors such as contracting (on which more investigation would be needed). The existence of spatial clusters of P-NT100\% holdings suggests that the spread of this farming model has been facilitated by the growth of networks among farmers and also other stakeholders within the landscape of extensive animal husbandry typical of Apennine areas (i.e. the Mid-Apennine White steer value chain); these networks probably helped to effectively adapt the technique to the different contexts also capitalizing the local tacit knowledge. This latter, actually, is reported by literature as an important element to consider in the interpretation of geographical concentration of innovation.

P-CA farm model seems also to be very contextualized, but the characteristics of the productive processes of P-CA holdings and their distribution at landscape scale suggest that the adoption of NT practices represents for these farms somehow a strong choice in alternative with the conventional farming practices and with what the majority of farms use to in agriculture. This (strong) choice seems to be mainly influenced by economic dimension (i.e. farm size) in two (Apulia and Sicily) out of the three spatial contexts where spatial autocorrelation of P-CA holdings is found. This factor do not seem to characterize the third spatial context (Emilia Romagna) and this evidence maybe recalls also for this context the relevance of the theme of contracting services. The existence of clusters of P-CA holdings suggests the existence of (formal and in-formal) networks devoted to adapt CA practices to the local contexts and to share information and know-how among farmers interacting with the local tacit knowledge. Localization and size induce to argue that economic factors are relevant for P-CA holdings too.

In the considered collectives of holdings, the presence of young farmers does not differ substantially from the average. In this sense it seems possible to hypothesize that this factor does not significantly influence the adoption of NT in a CA logic, even if further evidence is needed to corroborate this hypothesis. Apart from this aspect, it can be concluded that the choice of adopting NT within the new CA paradigm is significantly influenced by the factors considered in the conceptual framework, in particular the characteristics of the soil resource, the size and, above all, the construction of networks of farmers and other subjects.

This evidence rises the need to design diversified policy approaches for the different geographical contexts to support the spread of NT and of farmers' networks. These diversified approaches of policy should take into account economic/competitiveness aspects going beyond the sole environmental benefits of CA as nowadays acknowledged 
by the Second pillar of the Common agricultural policy. ${ }^{14}$ In the same way, support granted to farmers to shift from conventional to conservation agriculture provided in Italy by agri-environmental-climate compensation payments (Measure 10 of RDPs), to be more effective, should be completed by (or built upon) the support of other RDP measures such as the ones promoting information and training (Measure 1), advise to farmers (Measure 2) and supporting cooperation for innovation (Measure 16). The latter, in particular, seems to be the most suitable and promising in this perspective since it aims at facilitating the spread of innovation in agriculture by promoting hybrid networks and all the related knowledge spillovers as theorized by the EU European innovation partnership for agricultural productivity and Sustainability (EIP-AGRI).

The identification of clusters of NT holdings, as presented here in this paper, provides spatial indications that evidently require further in depth qualitative investigation (focus groups, brainstorming, interviews with farmers) in order to demonstrate the existence of the hypothesized networks and to identify the main driving forces of their aggregation processes. This investigation would contribute to fill the evident knowledge gap of the Census in relation with NT and CA and to better orientate at regional scale the policy-making process related to the spread of soil-friendly farming practices.

\section{Endnotes}

${ }^{1}$ There is no unique definition of innovation, despite many attempts have been made to reach it (see e.g. Baregheh et al. 2009).Definition of innovation is actually heavily dependent on the cultural context in which it is formulated. Anyway, innovation concerns with making changes in something established, especially by introducing new methods, ideas, or products (see Cambridge dictionary). In general terms, innovation is quite synonymous of technical change, even if the sense of this expression seems to be focused a little bit more on organizational change than other aspects.

${ }^{2}$ According to FAO (2014) Conservation Agriculture is an approach to managing agro-ecosystems for improved and sustained productivity. It is based on three key principles, namely: a) Continuous minimal mechanical soil disturbance (i.e. No-tillage (NT) / Minimum Tillage (MT) /Strip Tillage (ST) techniques), b) Permanent soil organic cover (i.e. crop residues and cover crops), c) crop rotation / combination / diversification on the field.

${ }^{3}$ EU Rural development policy forms Pillar 2 of the CAP. All Member States must prepare, implement and monitor a seven-year Rural development programme (RDP) at national and/or regional level. There are 118 RDPs in total for the period 2014-2020 across the EU. In contrast to Pillar 1 of the CAP, which is wholly financed by the EAGF, RDPs are partly funded by the EAFRD and co-financed by the Member State's national and/or regional authorities.

${ }^{4}$ Measure 10 (Agri-environment-climate payments to farmers) it's the only compulsory measure that must be made available throughout the Member State's or region's territory, in accordance with national, regional or local specific needs and priorities. It offers farmers and other land managers multi-annual contracts for agricultural practices that make a positive contribution to the environment and climate. The baseline above which payments are calculated includes CAP cross-compliance requirements. The Agri-environment-climate payment measure is of particular importance because it 
allows Member States to support implementation of appropriate soil management requirements through multi-annual contracts with individual farmers.

${ }^{5} \mathrm{~A}$ harrow is an implement for breaking up and smoothing out the surface of the soil. In this way it is distinct in its effect from the plow, which is used for deeper tillage. The purpose of harrowing is generally to break up clods (lumps of soil) and to provide a finer finish, a good tilth or soil structure that is suitable for seedbed use.

${ }^{6}$ Ecological effects of CA are mainly considered in terms of soil organic carbon (Chivenge et al. 2007) and in terms of carbon sequestration (Govaerts et al. 2009). NT in CA systems helps to sequester carbon in soil at a rate ranging from about 0.2 to $1.0 \mathrm{t} / \mathrm{ha} /$ year depending on the agro-ecological location and management practices (Corsi et al. 2012). Other important ecosystem services provided by CA are soil and water conservation (Palm et al. 2014). Water quality is improved due to reduced contamination levels from agrochemicals and soil erosion (Laurent et al. 2011). Complemented by other known good practices, including the use of quality seeds, and integrated pest, nutrient, weed and water management, $\mathrm{CA}$ is a base for sustainable agricultural production intensification. Ground water resources are replenished through better water infiltration and reduced surface runoff (Friedrich et al. 2012).

${ }^{7}$ Other barriers are: inadequate policies, for example, commodity based subsidies (EU, US) and direct farm payments (EU), unavailability of appropriate equipment and machines (many countries of the world), and of suitable herbicides to facilitate weed and vegetation management (especially for large scale farms in developing countries).

${ }^{8}$ The General Census of Agriculture is performed every ten years by the Italian National Institute of Statistics (ISTAT). It provides a wealth of detailed information on the structure of Italian agricultural and livestock holdings, broken down to municipal level. The period of data for the last Census of Agriculture (the 6th in Italy) is 24 October 2010. Data have been released by ISTAT in 2012.

${ }^{9}$ Elementary data have been provided by the Policy and Bioeconomy Centre of CREA that cooperates with Italian National Institute of Statistics (ISTAT).

${ }^{10}$ The differences described above are even more evident if we consider the UAA. In P-NT the UAA held by "individual firms" is 69\%. For the same entry, P-TOT accounts for $76 \%$. On the contrary, the amount of UAA held by "individual companies" and "other more complex typologies of companies" reaches in P-NT respectively $20,5 \%$ and $9 \%$ (vs. 9,5\% and 3\% respectively accounted for P-TOT).

${ }^{11} \mathrm{~A}$ particular concentration has been found in Marche, Umbria, Toscana and the eastern part of Emilia Romagna.

${ }^{12}$ Our processing tools have been two free source software: R (https://www.r-project. org) and $\mathrm{GeoDa}^{\circ}$ (http://geodacenter.github.io).

${ }^{13} \mathrm{We}$ report, in the last column, the pseudo $p$-values obtained through the randomization procedure, in particular 9999 random permutations of the observed values to test their possible departure from randomness. As it can be observed, there is an evident positive spatial autocorrelation at global level in both groups of NT holdings, but at this point it is important to stress that a significant global Moran statistic 
may hide large spatial patches of no autocorrelation and/or even clusters of negative autocorrelation, particularly in cases like our, with so many spatial units.

${ }^{14}$ In this sense, some recent limitations to the use of plant protection products (i.e. herbicides) would also need to be rethought not only in the light of making CA more environmentally sustainable, but also for making it more economically attractive and effective for farmers.

\section{Abbreviations}

A-UAA: Arable Utilized Agricultural Area expressed in hectares (ha). It represent the part of the land devoted by the farm holding to the cultivation of sole (annual crops - (cropland); CA: Conservation agriculture; CAP: Common agricultural policy; CT: Conventional tillage; EAFRD: European Agricultural Fund for Rural Development; EAGF: European Agricultural Guarantee Fund; EIP: The European Innovation Partnership for Agricultural productivity and Sustainability (EIP-AGRI) https://ec.europa.eu/agriculture/research-innovation/eip-agriculture_nl; EU: European Union; MT: Minimum tillage; NT: No-till (No-Tillage; Zero tillage); P-CA: The most restricted collective of NT holdings (n. 5.328) deriving from filtering operation n. 4. In consideration of the combination a series of variables, it is assumed that P-CA holdings are the ones that are more probably practicing NT under "real" CA schemes in Italy; P-NT ONLY: Population of NT holdings (n. 27.338) deriving from filtering operation n. 1 performed on P-NT; P-NT: The wider collective of NT holdings ( $\mathrm{n}$. 52.218) deriving directly from Census. It's made of holdings declaring to have a A-UAA under NT greater than zero hectares. It represents the population of holdings on which all the subsequent filtering operations have been performed; P-NT100\%: Population of NT holdings (n. 21.033) deriving from filtering operation n. 2 performed on P-NT ONLY; P-NT100\%NoC-V: Population of NT holdings ( $n$. 19.498) deriving from filtering operation $n .3$ performed on PNT100\%; P-TOT: The total population of holdings (1,62 million) surveyed by the Agricultural Census in 2010; RDP: Rural Development Programme(s); ST: Strip tillage; UAA: Utilized agricultural area expressed in hectares (ha). It represents the overall land cultivated by the agricultural holdings for every kind of cultivation (annual and perennial crops)

\section{Acknowledgements}

Special thanks for the provision of the Census elementary data set go to Concetta Cardillo, researcher at CREA-PB.

Funding

No specific additional sources of funding have been used for the research.

\section{Availability of data and materials}

The datasets analyzed during the current study are available in the CREA repository on the basis of a special agreement among CREA and ISTAT concerning Census microdata. The datasets are not publicly available but are available from the corresponding author on reasonable request.

\section{Authors' contributions}

This paper is the result of teamwork among the authors. In detail, they respectively took responsibility for the following sections: DM (Thematic framework and objective; No-till as a component of a new farming system: the conservation agriculture; Data sources and elementary data), AB (Results and discussion), LR (Methods: filtering procedures and spatial distribution of NT holdings), Cl (Hypotesis suggested by the socio-economic literature; The conceptual framework; Conclusions). LR also cured data processing and chart drawing. All authors read and approved the final manuscript.

\section{Competing interests}

We declare that we have no significant competing financial, professional, or personal interests that might have influenced the performance or presentation of the work described in this manuscript.

\section{Publisher's Note}

Springer Nature remains neutral with regard to jurisdictional claims in published maps and institutional affiliations.

\section{Author details}

${ }^{1}$ Research Centre for Policy and Bioeconomy, Council for Agricultural Research and Economics (CREA), Rome, Italy. ${ }^{2}$ Department of Agricultural, Environmental and Food Sciences, University of Molise, Via De Sanctis, 86100

Campobasso, Italy. ${ }^{3}$ Department of Economy, University of Molise, Campobasso, Italy.

Received: 7 February 2018 Accepted: 25 March 2019

Published online: 23 April 2019

\section{References}

Andersson JA, D'Souza S (2014) From adoption claims to understanding farmers and contexts: a literature review of conservation agriculture (CA) adoption among smallholder farmers in southern Africa. Agric Ecosyst Environ 187:116-132 Anselin L (1995) Local indicators of spatial association - LISA. Geogr Anal 27(2):93-115

Awotide BA, Karimov AA, Diagne A (2016) Agricultural technology adoption, commercialization and smallholder rice farmers' welfare in rural Nigeria. Agric Food Econ 4(3). https://doi.org/10.1186/s40100-016-0047-8. 
Baker CJ, Saxton KE, Ritchie WR, Chamen WCT, Reicosky DC, Ribeiro MFS, Justice SE, Hobbs PR (2007) No-tillage seeding in conservation agriculture (2nd ed.) CABI and FAO. Cromwe Press, Trowbridge, p 326 Available online at: http://www.fao. org/3/al298e/al298e00.htm

Baregheh A, Rowley J, Sambrook S (2009) Towards a multidisciplinary definition of innovation. Manag Decis 47(8)

Chivenge PP, Murwira HK, Giller KE, Mapfumo P, Six J (2007) Long-term impact of reduced tillage and residue management on soil carbon stabilization: implications for conservation agriculture on contrasting soils. Soil Tillage Res 94:328-337

Corsi S, Friedrich T, Kassam A, Pisante M, de Moraes Sà J (2012) Soil organic carbon accumulation and greenhouse gas emission reductions from conservation agriculture: a literature review. In: Integrated crop management Vol. 16. FAO, Rome, p 89

Coughenour CM (2003) Innovating conservation agriculture: the case of no-till cropping. Rural Sociol 68(2):278-304

Coughenour CM, Chamala S (2000) Conservation tillage and cropping innovation constructing the new culture of agriculture. lowa State University Press, Ames

Crabtree B (2010) Search for sustainability with No-Till Bill in dryland agriculture. Crabtree Agricultural Consulting, Australia, 204 pp. https://trove.nla.gov.au/work/37376212?q\&versionld=48732661

Cramb RA (2005) Social capital and soil conservation: evidence from the Philippines. Aust J Agric Resour Econ 49:211-226

D'souza A, Mishra AK (2016) Adoption and abandonment of conservation Technologies in Developing Economies: the case of South Asia. Selected paper prepared for presentation at the 2016 Agricultural \& Applied Economics Association Annual Meeting, Boston July 31-August 2

de Janvry A, Fafchamps M, Sadoulet E (1991) Peasant household behavior with missing markets: some paradoxes explained. Econ J 101:1400-1417. https://doi.org/10.2307/2234892

Derpsch R (2008) No-tillage and conservation agriculture: a Progress report. In: Goddard T, Zoebisch MA, Gan YT, Ellis W, Watson A, Sombatpanit S (eds) No-till farming systemsSpecial Publication $N^{\circ} 3$. World Association of Soil and Water Conservation, Bangkok, pp 7-39 isbn:ISBN:978-974-8391-60-1

Derpsch R, Friedrich T (2009) Global overview of conservation agriculture no-till adoption. 4th world congress on conservation agriculture, New Delhi 4 - 7 February

Dosi G (1982) Technological paradigms and technological trajectories. Res Policy 11:147-162

Dosi G, Freeman C, Nelson R, Silverberg G, Soete L (1988) The paradigm of conservation tillage. Proc. world Assoc. soil and water ConservP1. In: Dumanski J, Peiretti R, Benetis J, McGarry D, Pieri C (eds) Technical change and economic theory. Pinter Publishers, London and New York, pp 58-64

Duranton G, Puga D (2001) Nursery cities: urban diversity, process innovation, and the life cycle of products. Am Econ Rev 91(5):1454-1477. https://doi.org/10.1257/aer.91.5.1454

FAO (2001) The economics of conservation agriculture. Food and Agriculture Organization Natural Resources Management and Environment Department. FAO Corporate Document Depository, Rome.

FAO (2008) Investing in sustainable crop intensification: the case for soil health. Report of the international technical workshop. FAO, Rome Integrated Crop Management. Vol. 6. Rome: FAO. Online at: http://www.fao.org/3/i0951e/ i0951e00.pdf

FAO (2014) The three principles of conservation agriculture. Available online at: http://www.fao.org/assets/infographics/CAprinciples-Infographic.pdf.

Friedrich T, Derpsch R, Kassam A (2012) Overview of the Global Spread of Conservation Agriculture. Field Actions Science Reports. Special Issue 6/2012. URL: https://journals.openedition.org/factsreports/1941.

Friedrich T, Kassam AH, Shaxson F (2009) Conservation agriculture. In: agriculture for developing countries. Science and technology options assessment (STOA) project. European Technology Assessment Group, Karlsruhe

Govaerts B, Verhulst N, Castellanos-Navarrete A, Sayre KD, Dixon J, Dendooven L (2009) Conservation agriculture and soil carbon sequestration: between myth and farmer reality. Crit Rev Plant Sci 28:97-122

Guccione G. Schifani G. (2001). Technological innovation. Agricultural mechanization and the impact on the environment: sod seeding and minimum tillage. MEDIT N³.

Guidobono Cavalchini A, Rognoni GL, Tangorra FM, Costa A (2013) Experimental tests on winter cereal: sod seeding compared to minimum tillage and traditional plowing. J Agric Eng Res XLIV(s1):e79

Gupta R, Sayre K (2007) Conservation agriculture in South Asia. J Agric Sci 145:207-214

Hoover EM (1937) Location theory and the shoe and leather industry di Harvard economic studies, volume 55. Harvard University Press, Cambridge

levoli C, Basile RG, Belliggiano A (2017) The spatial patterns of dairy farming in Molise. Eur Countryside 9(4):729-745

Kassam A., Friedrich T., Derpsch R. and Kienzle J. (2015). Overview of the worldwide spread of conservation agriculture. Field Actions Science Reports [Online], Vol. 8/2015. Online since 26 September 2015, connection on 30 September 2016. URL: https://journals.openedition.org/factsreports/3966

Knickel K, Brunori G, Rand S, Proost J (2009) Towards a better conceptual framework for innovation processes in agriculture and rural development: from linear models to systemic approaches. J Agric Educ Ext 15(2):131-146. https://doi.org/10.1080/13892240902909064

Knowler D, Bradshaw B (2007) Farmers' adoption of conservation agriculture: a review and synthesis of recent research. Food Policy 32:25-48

Laurent F., Leturcq G., Mello I., Corbonnois J., Verdum R. (2011). La diffusion du semis direct au Brésil. diversité des pratiques et logiques territoriales: l'exemple de la région d'Itaipu au Paraná. Confins 12 [online]. URL: https://journals.openedition. org/confins/7143

Letaa E, Kabungo C, Katungi E, Ojara M, Ndunguru A (2015) Farm level adoption and spatial diffusion of improved common bean varieties in southern highlands of Tanzania. Afr Crop Sci J 23(3):261-277

Lindwall CW, Sonntag B (eds) (2010) Landscape transformed: the history of conservation tillage and direct seeding. Knowledge Impact in Society. University of Saskatchewan, Saskatoon

Lundvall B-A (1995) National Systems of innovation: towards a theory of innovation and interactive learning. Pinter Publishers, London

Marandola D, Marongiu S (2012) Più efficienza al Centro-Sud con la semina su Sodo. L'Informatore Agrario 40:75-78 
Moore KM, Lamb JN, Sikuku DN, Ashilenje DS, Laker-Ojok R, Norton J (2014) Multiple knowledges for agricultural production: implications for the development of conservation agriculture in Kenya and Uganda. J Agric Educ Ext 20(3):291-307

Nyanga PH, Johnsen FH, Aune JB, Kalinda TH (2011) Smallholder farmers' perceptions of climate change and conservation agriculture: evidence from Zambia. J Sustain Dev 4(4):73-85

Palm C, Blanco-Canqui H, De Clerck F, Gatere L, Grace P (2014) Conservation agriculture and ecosystem services: an overview. Agric Ecosyst Environ 187:87-105

Rogers E. M. (1962). Diffusion of innovations. First edition. New York. Free Press.

Saturnino HM, Landers JN (2002) The environment and zero tillage. APDC-FAO, BrasiliaUDC, p 139

SCAR EU (2012) Agricultural knowledge and innovation systems in transition - a reflection paper, European perspectives on rural development. Van Gorcum, Assen

Simtowe F, Asfaw S, Abate T (2016) Determinants of agricultural technology adoption under partial population awareness: the case of pigeonpea in Malawi. Agric Food Econ 4:7. https://doi.org/10.1186/s40100-016-0051-z

Sorrenson WJ, Montoya LJ (1984) Implicaçoes econômicas da erosao do solo e de practices conservacionistas no Paraná. GTZ and IAPAR, Londrina and Eschborn, p 231

Van den Putte A, Govers G, Diels J, Gillijns K, Demuzere M (2010) Assessing the effect of soil tillage on crop growth: a meta-regression analysis on European crop yields under conservation agriculture. Europ J Agron 33:231-241

Van der Ploeg JD (2003) The virtual farmer. Past, present and future of the Dutch peasantry. Series: European perspectives on rural development. Van Gorcum, Assen

Submit your manuscript to a SpringerOpen ${ }^{\circ}$ journal and benefit from:

- Convenient online submission

- Rigorous peer review

- Open access: articles freely available online

- High visibility within the field

- Retaining the copyright to your article

Submit your next manuscript at $>$ springeropen.com 